\title{
The $-514 \mathrm{C} / \mathrm{T}$ polymorphism in the hepatic lipase gene promoter is associated with insulin sensitivity in a healthy young population
}

\author{
Purificación Gómez, Francisco Pérez-Jiménez, Carmen Marín, Juan Antonio Moreno, \\ María José Gómez, Cecilia Bellido, Pablo Pérez-Martínez, Francisco Fuentes, \\ Juan Antonio Paniagua and José López-Miranda
}

Unit of Lipids and Arteriosclerosis, Hospital Universitario Reina Sofia, 14004 Córdoba, Spain

(Requests for offprints should be addressed to J López-Miranda; Email: jlopezmir@uco.es)

\begin{abstract}
Impaired insulin action has been associated with diabetes, dyslipidemia and atherosclerotic vascular disease. The expression of insulin resistance results from the interaction of environmental and genetic factors. Human hepatic lipase $(\mathrm{HL})$ is a lipolytic enzyme that plays a role in the metabolism of several lipoproteins, while insulin up-regulates the activity of $\mathrm{HL}$ via insulin-responsive elements in the $\mathrm{HL}$ promoter. We have examined the influence of $-514 \mathrm{C} / \mathrm{T}$ polymorphism in the hepatic lipase gene promoter on insulin sensitivity in 59 healthy young subjects (30 males and 29 females). The volunteers were subjected to three dietary periods, each lasting four weeks. During the first period all subjects consumed a saturated fat (SFA)-enriched diet with $38 \%$ as fat $(20 \%$ SFA, $12 \%$ monounsaturated fatty acids (MUFA) and $6 \%$ polyunsaturated fatty acids (PUFA)). In the second and third dietary periods, a randomized crossover design was used, consisting of a low fat, high carbohydrate diet (CHO diet) ( $<10 \%$ SFA, $12 \%$ MUFA and $6 \%$ PUFA) and a high-MUFA, or Mediterranean diet, with $<10 \%$ SFA, $22 \%$ MUFA and $6 \%$ PUFA. We determined the in vivo insulin resistance using the insulin suppression test with somatostatin. Steady-state plasma glucose (SSPG) concentrations (a measure of insulin sensitivity) were significantly higher in men carriers of the $-514 \mathrm{~T}$ allele after the consumption of the SFA diet than after the $\mathrm{CHO}$ diet and the Mediterranean diet. This effect was not observed in women. Moreover, there were no significant differences in insulin sensitivity after the three diets in men and women with the CC genotype. In summary, our results show an improvement in insulin sensitivity in men with the $-514 \mathrm{~T}$ allele of the HL promoter polymorphism, when MUFA and carbohydrates are consumed instead of SFA fat.
\end{abstract}

Journal of Molecular Endocrinology (2005) 34, 331-338

\section{Introduction}

Impaired insulin action has been associated with diabetes, obesity, dyslipidemia, hypertension and also with atherosclerotic vascular disease. Insulin resistance is determined by the interaction between genetic and environmental factors. In general, high intake of dietary fat has been associated with obesity and its comorbid conditions, including heart disease and diabetes. All these factors are related to the global process of 'Westernization' of lifestyles and dietary habits, especially the high intake in calories from saturated fat. Insulin resistance usually precedes the diagnosis of type 2 diabetes mellitus by decades and, in most cases, the clinical expression of the disease could be prevented by dietary and lifestyle modification (Mayer-Davis et al. 1997). On the other hand, the genetic base of type 2 diabetes mellitus is very heterogeneous and has been related to various genetic mutations that codify proteins connected with glucose and insulin metabolism, such as the insulin receptor (Kusari et al.
1991), insulin receptor substrate-1 (Almind et al. 1993), the Rad protein (Reynet \& Kahn 1993), the glycogen synthase (Bjorbaek et al. 1994) and the $\beta$-3-adrenergic receptor (Walston et al. 1995), to mention the most well-known. However, the genetic background of insulin resistance and type 2 diabetes mellitus is more complex and it can also involve other genes seemingly unrelated with carbohydrate metabolism.

Hepatic lipase (HL) is an enzyme anchored to the vascular endothelium in the liver as well as to the surface of hepatocytes, where it catalyzes the hydrolysis of various lipids in lipoprotein particles. Several studies have reported that the $-514 \mathrm{~T}$ allele of the HL gene promoter appears to be associated with decreased HL activity, increased high density lipoprotein cholesterol (HDL-C) (Guerra et al. 1997, Zambon et al. 1998), and increased low density lipoprotein (LDL) buoyancy (Zambon et al. 1998). However, at present, the effects of this common hepatic lipase variant $-514 \mathrm{C} / \mathrm{T}$ on lipid and lipoprotein levels are not well known. Moreover, as $\mathrm{HL}$ is involved in the clearance of triglyceride-rich 
lipoproteins, the primary effects of the variant genes influence the metabolism of triglyceride-rich lipoproteins which may, secondarily, affect glucose homeostasis. Also, insulin has been assumed to upregulate the activity of the HL promoter. This has been proposed to explain the associations between hyperinsulinemia and high HL activity (Romano et al. 1997). Recently, in a Finnish population, an association of the HL variant with insulin resistance was observed in patients with familial combined hyperlipidemia (Pihlajamaki et al. 2000).

Whether the HL promoter variant contributes to impaired insulin sensitivity in the normal population has not been investigated. In the present study we have explored the possible influence of the $-514 \mathrm{C} / \mathrm{T}$ variant in the promoter of the HL gene on insulin sensitivity in a healthy young population. In addition, the interaction between this polymorphism and diet on insulin sensitivity was evaluated.

\section{Materials and methods}

\section{Subjects and diets}

Fifty-nine healthy normolipemic subjects, 39 homozygous for the most common allele $(\mathrm{C} / \mathrm{C})$ and 20 carriers of the $\mathrm{T}$ allele (CT/TT), attending the University of Cordoba volunteered to participate in the study. They ranged in age from $22 \cdot 6 \pm 1 \cdot 4$ years. None of them had diabetes, or liver, renal or thyroid disease. All underwent a comprehensive medical history, physical examination, and clinical chemistry analysis before enrollment. None of the subjects was taking medication or vitamins known to affect plasma lipids. Dietary information, including alcohol consumption, was collected over seven consecutive days. Individual energy requirements were calculated by taking into consideration each subject's weight and physical activity. Subjects were encouraged to maintain their regular physical activity and life-style and were asked to record in a diary any event that could affect the outcome of the study, such as stress, change in smoking habits, and alcohol consumption or foods not included in the experimental design as described in our previous studies (Fuentes et al. 2001, Pérez-Jiménez et al. 2001, Pérez-Martínez et al. 2001).

The study design included an initial 28-day period during which all the subjects consumed a saturated fat (SFA)-enriched diet with $15 \%$ of energy as protein, $47 \%$ as carbohydrate, and $38 \%$ as fat $(20 \%$ SFA, $12 \%$ monounsaturated fatty acids (MUFA) and 6\% polyunsaturated fatty acids (PUFA)). All participants were then randomized in a crossover design and exposed to two new dietary periods: a low fat, high carbohydrate diet (CHO diet), and a high-MUFA diet, with a typical 'Mediterranean diet' enriched with olive oil. The two groups of subjects were assigned one of the two dietary regimes for 28 days each. Group 1 (30 subjects) was placed on a Mediterranean diet followed by a CHO diet. For group 2 (29 subjects) the order was reversed. Assignment of volunteers to the sequence of diets was carried out at random. The CHO diet (National Cholesterol Education Program 1994) contained 15\% of energy as protein, $57 \%$ as $\mathrm{CHO}$, and $28 \%$ as fat $(<10 \%$ SFA, 12\% MUFA, and 6\% PUFA). The Mediterranean diet contained $15 \%$ of energy as protein, $47 \%$ as $\mathrm{CHO}$, and $38 \%$ as fat $(<10 \%$ SFA, $22 \%$ MUFA, and $6 \%$ PUFA). Olive oil provided $75 \%$ of total MUFA consumed during this last dietary period. Dietary cholesterol was maintained constant in our experimental design and the mean cholesterol intake was $115 \mathrm{mg}$ / $1000 \mathrm{kcal}$ during the three periods. The Human Investigation Review Committee approved this study at the Reína Sofia University Hospital. Informed consent was obtained from all participants.

The composition of the experimental diets was calculated using the United States Department of Agriculture (USDA) (Human Nutrition Information Service of Department of Agriculture 1987) food tables, or the Spanish food composition tables for local foodstuffs. Fourteen menus, prepared with regular solid foods, were rotated during the experimental period. We used virgin olive oil for cooking and salad dressing during the Mediterranean diet, and palm oil and butter for the high-SFA diet. During the CHO diet period, biscuits, bread and jam replaced some olive oil or palm oil. Lunch and dinner were consumed in the hospital dining room, whereas breakfast and an afternoon coffee break were eaten in the medical school cafeteria. A dietician supervised all meals. Duplicate samples from each menu were collected, homogenized, and stored at $-80^{\circ} \mathrm{C}$. Protein, fat and $\mathrm{CHO}$ content of the diet were analyzed using standard methods (Association of Official Analytical Chemists, Arlington 1990). Evaluation of dietary compliance was also performed by examining the food diaries and by analyzing the fatty acid content of the cholesterol ester fraction in LDL (Ruiz-Gutierrez et al. 1993).

\section{Blood sampling and biochemical determinations}

Venous blood for insulin, glucose, lipid and lipoprotein analysis was collected in EDTA-containing tubes from the subjects after a 12-h overnight fast at the end of each dietary period. Each analysis was performed three times. Total cholesterol (TG) and triglycerides (TG) were assayed by enzymatic procedures (Allain et al. 1974, Bucolo \& David et al. 1973). HDL-C was measured by analyzing the supernatant obtained after precipitation of a plasma aliquot with dextran sulfate- $\mathrm{Mg}^{2+}$ (Warnick et al. 1982). The LDL-cholesterol (LDL-C) level was calculated from total cholesterol, triglyceride, and HDL-C values using the Friedewald formula (Friedewald et al. 1972). Unesterified free fatty acid (FFA) 
levels were determined by an enzymatic colorimetric assay (Boehringer Mannheim) as described by Shimizu et al. (1979). To reduce inter-assay variation, plasma for biochemical determinations was stored at $-80{ }^{\circ} \mathrm{G}$ and analyzed in duplicate at the end of the study.

\section{Glucose suppression test}

At the end of each dietary period all subjects underwent a modified insulin suppression test (Harano et al. 1977, Laws et al. 1994). The technique used in the present study to quantify insulin sensitivity was the insulin suppression test, a simple and cost-effective test for the measurement of insulin resistance, which has been used increasingly often in recent years. The study began at $0800 \mathrm{~h}$, after a 12-h fast. A continuous infusion of somatostatin $(214 \mathrm{nmol} / \mathrm{h})$, insulin $\left(180 \mathrm{pmol} / \mathrm{m}^{2} / \mathrm{min}\right)$, and glucose $\left(13.2 \mathrm{mmol} / \mathrm{m}^{2} / \mathrm{min}\right)$ was administered in the same vein. Somatostatin was used to inhibit endogenous insulin secretion. Blood was sampled every $30 \mathrm{~min}$ for the first 2.5 hours, by which time steady-state plasma glucose (SSPG) and steady-state plasma insulin (SSPI) levels were achieved. Blood was then sampled at 10-min intervals for the last $30 \mathrm{~min}$ (at 150, 160, 170 and $180 \mathrm{~min}$ ) for measurement of plasma glucose and insulin concentrations. These four values determined the SSPG and SSPI concentrations. Since SSPI levels were similar in all subjects, SSPG levels provided a measure of the ability of insulin to promote disposal of infused glucose. Subjects with high SSPG are relatively more insulin-resistant than those with lower SSPG.

\section{Genotyping of hepatic lipase gene polymorphism}

DNA was extracted from $10 \mathrm{ml}$ EDTA-containing blood. Amplification of a 299-bp region of the hepatic lipase gene was carried out by polymerase chain reaction (PCR) with $250 \mathrm{ng}$ genomic DNA and $0 \cdot 2 \mu \mathrm{mol}$ of each oligonucleotide primer $(\mathrm{P1}$; 5'-AAGAAGTGTGTTTA CTCTAAGGATCA-3', and P2, 5'-GGTGGCTTCGA CGTGGGTGCGTAAG-3') in $50 \mu \mathrm{l}$. DNA was denaturated at $95^{\circ} \mathrm{C}$ for $5 \mathrm{~min}$ followed by 30 cycles of denaturation at $95{ }^{\circ} \mathrm{C}$ for $1 \mathrm{~min}$, annealing at $58^{\circ} \mathrm{C}$ for $1.5 \mathrm{~min}$, and extension at $72^{\circ} \mathrm{C}$ for $2 \mathrm{~min}$. The PCR product $(10 \mu \mathrm{l})$ was digested with 5 units of restriction enzyme NlaIII (BRL, Baltimore, MA, USA) in a total volume of $35 \mu \mathrm{l}$. Digested DNA was separated by electrophoresis in an 8\% non-denaturing polyacrylamide gel at $150 \mathrm{~V}$ for $2 \mathrm{~h}$. Bands were visualized after silver staining. Samples containing the $\mathrm{T}$ allele were amplified a second time to verify the genotype.

\section{Statistical analysis}

Statistical analyses were carried out using the SPSS statistical package (SPSS, Chicago, IL, USA). ANOVA for repeated measures was used to analyze the differences in plasma lipid, glucose, SSPG levels and basal glucose and insulin-stimulated glucose uptake between dietary phases. When statistically significant effects were demonstrated, Tukey's post-hoc test was used to identify between-group differences. The general linear models for repeated measures procedure was used to test gene and diet interactions. A value of $P<0 \cdot 05$ was considered significant.

\section{Results}

Dietary composition was analyzed in duplicate meals portions, and the results are shown in Table 1. The results were in good agreement with values obtained from the food composition tables. Analysis of the cholesterol ester fraction of plasma LDL showed good adherence to the different diets. During consumption of the SFA diet, there was a significant increase in palmitic acid (16:0) compared with that recorded during the high $\mathrm{CHO}$ and Mediterranean dietary periods $(27 \cdot 2 \pm 1 \cdot 4$ vs $18 \cdot 9 \pm 3 \cdot 9, \quad P<0 \cdot 004$ and $27 \cdot 2 \pm 1 \cdot 4$ vs $15 \cdot 1 \pm 0 \cdot 4$, $P<0.004$ respectively). We also observed a significant increase in oleic acid (18:1) when subjects switched from the $\mathrm{CHO}$ diet to the Mediterranean diet $(38.5 \pm 9 \cdot 0$ vs $49 \cdot 7 \pm 4 \cdot 7, P<0 \cdot 05)$.

The baseline characteristics of the subjects according to the $-514 \mathrm{C} / \mathrm{T}$ polymorphism are shown in Table 2 . Carriers of the $-514 \mathrm{~T}$ allele $(n=20)$ had greater total cholesterol (TC) and LDL-C plasma levels compared with homozygotes for the $\mathrm{C}$ allele $(n=39)$. There were no significant differences between subjects with the CG genotype and those with the CT/TT genotype for any of the lipid parameters after the three dietary periods (Table 3).

Steady state plasma glucose (SSPG) concentrations (a measure of insulin sensitivity) were significantly higher in men carriers of the $-514 \mathrm{~T}$ allele after the consumption of the saturated diet than after the CHO diet $(P<0 \cdot 05)$ and the Mediterranean diet $(P<0 \cdot 05)$ (Fig. 1A), but this was not so in women (Fig. 1B). Moreover, there were no significant differences in insulin sensitivity after the three diets in subjects with the CG genotype, either in men or women (Fig. 1A,B). Analysis of plasma FFAs revealed that homozygotes for the $\mathrm{C}$ allele showed lower levels of FFAs following the $\mathrm{CHO}$ and the Mediterranean diets, as compared with the saturated diet $(0.47 \pm 0.08$ vs $0.58 \pm 0.09, P<0.02$ and $0.41 \pm 0.06$ vs $0.58 \pm 0.09$, $P<0.001$ respectively). The same effect was observed in carriers of the $-514 \mathrm{~T}$ allele, but a significant difference was noted only between the SFA diet and the CHO diet $(0 \cdot 61 \pm 0.09$ vs $0.54 \pm 0 \cdot 01, P=0 \cdot 01)$. Furthermore, total cholesterol, LDL-C, and apolipoprotein B plasma levels were correlated positively with SSPG $(\mathrm{r}=0 \cdot 22, P<0 \cdot 001$, $\mathrm{r}=0.30, P<0.001$, and $\mathrm{r}=0.35, P<0.001$ respectively). 
Table 1 Mean daily intake during each experimental diet period (mean \pm S.D.). SFA diet, saturated fat enriched diet; CHO-diet, low fat, high carbohydrate diet

\begin{tabular}{|c|c|c|c|}
\hline & High SFA diet & CHO diet & $\begin{array}{l}\text { Mediterranean } \\
\text { diet }\end{array}$ \\
\hline \multicolumn{4}{|c|}{ Protein (\% of energy intake) } \\
\hline Calculated & 15 & 15 & 15 \\
\hline Analyzed & $18 \cdot 1 \pm 2 \cdot 5$ & $17 \cdot 6 \pm 1 \cdot 5$ & $17 \cdot 5 \pm 2 \cdot 0$ \\
\hline \multicolumn{4}{|c|}{ Fat (\% of energy intake) } \\
\hline \multicolumn{4}{|c|}{ Saturated } \\
\hline Calculated & 20 & 10 & 10 \\
\hline Analyzed & $22 \cdot 6 \pm 4 \cdot 1$ & $9 \cdot 2 \pm 3 \cdot 5$ & $9 \cdot 2 \pm 4 \cdot 2$ \\
\hline \multicolumn{4}{|c|}{ Monounsaturated } \\
\hline Calculated & 12 & 12 & 22 \\
\hline Analyzed & $10 \cdot 1 \pm 2 \cdot 9$ & $13 \cdot 5 \pm 1 \cdot 2$ & $24 \cdot 4 \pm 2 \cdot 2$ \\
\hline \multicolumn{4}{|c|}{ Polyunsaturated } \\
\hline Calculated & 6 & 6 & 6 \\
\hline Analyzed & $5 \pm 1.5$ & $5 \cdot 2 \pm 2 \cdot 0$ & $4 \cdot 8 \pm 1 \cdot 1$ \\
\hline \multicolumn{4}{|c|}{ Carbohydrates ( $\%$ of energy intake) } \\
\hline Calculated & 47 & 57 & 47 \\
\hline Analyzed & $44 \cdot 2 \pm 8 \cdot 3$ & $54 \cdot 5 \pm 8 \cdot 6$ & $44 \cdot 1 \pm 7 \cdot 8$ \\
\hline \multicolumn{4}{|c|}{ Cholesterol (mg/day) } \\
\hline Calculated & 115 & 115 & 115 \\
\hline Analyzed & $112 \pm 39$ & $113 \pm 48$ & $117 \pm 42$ \\
\hline \multicolumn{4}{|l|}{ Energy (MJ) } \\
\hline Calculated & $10 \cdot 2$ & $10 \cdot 2$ & $10 \cdot 2$ \\
\hline Analyzed & $10 \cdot 8 \pm 1 \cdot 1$ & $10 \cdot 6 \pm 1 \cdot 0$ & $10 \cdot 8 \pm 1 \cdot 5$ \\
\hline \multicolumn{4}{|c|}{ Dietary fiber (g/day) } \\
\hline Calculated & 30 & 30 & 30 \\
\hline Analyzed & $25 \cdot 9 \pm 7 \cdot 0$ & $26 \cdot 1 \pm 6 \cdot 1$ & $24 \cdot 9 \pm 8 \cdot 2$ \\
\hline
\end{tabular}

Additionally, there was a significant inverse correlation between mean glucose levels of the SSPG and HDL-G plasma levels $(\mathrm{r}=-0 \cdot 20, P<0 \cdot 05)$.

\section{Discussion}

Several exogenous factors such as diet play an important role in the peripheral effect of insulin, although it is now thought that there is genetically determined individual

Table 2 Baseline characteristics of the subjects according to the $-514 \mathrm{C} / \mathrm{T}$ polymorphism. Value are means \pm S.D.

\begin{tabular}{|c|c|c|c|}
\hline & CC $(n=39)$ & CT/TT $(n=20)$ & $P^{*}$ \\
\hline Age & $22 \cdot 3 \pm 1 \cdot 30$ & $23 \cdot 0 \pm 1 \cdot 50$ & 0.21 \\
\hline Body mass index & $20 \cdot 9 \pm 2 \cdot 70$ & $22 \cdot 2 \pm 3 \cdot 28$ & 0.21 \\
\hline Total cholesterol & $4.02 \pm 0.65$ & $4.47 \pm 0.56$ & 0.01 \\
\hline Triglycerides & $0.69 \pm 0.31$ & $0.71 \pm 0.22$ & 0.83 \\
\hline LDL-C & $2.33 \pm 0.58$ & $2 \cdot 72 \pm 0.70$ & 0.03 \\
\hline HDL-C & $1 \cdot 36 \pm 0 \cdot 31$ & $1.42 \pm 0.43$ & 0.60 \\
\hline Apo B & $1.74 \pm 0.65$ & $1.66 \pm 0.48$ & 0.66 \\
\hline Apo Al & $1 \cdot 38 \pm 0.49$ & $1.26 \pm 0.45$ & 0.41 \\
\hline
\end{tabular}

${ }^{*} P$ values calculated by ANOVA.

Apo, apolipoprotein. variability in the development of insulin resistance (Moller et al. 1996). The novel finding of the present study is that the $-514 \mathrm{C} / \mathrm{T}$ polymorphism in the HL promoter is associated with a decrease in insulin sensitivity in normal young males after consuming an SFA diet. Thus the replacement of this diet by a CHO diet or a Mediterranean diet improved insulin sensitivity in male $-514 \mathrm{~T}$ carriers.

The saturated fatty acids reduce insulin sensitivity in type 2 diabetes patients (Moller et al. 1996, Purnell \& Brunzell 1997) and in healthy subjects as shown in a recent study carried out by our group (Pérez-Jiménez et al. 2001). Furthermore, it has also been suggested that hypertriglyceridemia and an SFA diet might favor insulin resistance (Steiner et al. 1991, Storlien et al. 1993), increasing FFAs, which may inhibit glucose utilization by peripheral cells, thus reducing insulin sensitivity (Bjontorp 1994). In addition, there is a stronger interindividual variability in the response to dietary fat, as we show in our present study. This suggests that differences in gene products involved in candidate metabolic pathways produce phenotypic differences in response to dietary changes. Although it is well known that nutrients are involved in modulating the metabolism of lipoproteins, these aspects have been poorly 
Table 3 Levels of plasma lipids, lipoprotein and other metabolic parameters according to $-514 \mathrm{C} / \mathrm{T}$ polymorphism after each of the dietary periods. SFA diet, saturated fat enriched diet; CHO-diet, low fat, high carbohydrate diet. Values are means \pm S.D.

\begin{tabular}{|c|c|c|c|c|c|c|c|}
\hline & Diet & $\begin{array}{l}\text { Total } \\
\text { cholesterol }\end{array}$ & LDL-C & ApoB & Triglycerides & HDL-C & ApoA-I \\
\hline $\begin{array}{l}\text { Genotype } \\
\text { CC }(n=39)\end{array}$ & $\begin{array}{l}\text { SFA } \\
\text { CHO } \\
\text { Mediterranean }\end{array}$ & $\begin{array}{l}4 \cdot 10 \pm 0 \cdot 61 \\
3 \cdot 59 \pm 0 \cdot 60 \\
3 \cdot 65 \pm 0 \cdot 64\end{array}$ & $\begin{array}{l}2.51 \pm 0.51 \\
2 \cdot 11 \pm 0.53 \\
2 \cdot 13 \pm 0.53\end{array}$ & $\begin{array}{l}71 \pm 12 \\
64 \pm 12 \\
64 \pm 10\end{array}$ & $\begin{array}{l}0.57 \pm 0.26 \\
0.71 \pm 0.30 \\
0.71 \pm 0.28\end{array}$ & $\begin{array}{l}1 \cdot 27 \pm 0 \cdot 23 \\
1 \cdot 13 \pm 0 \cdot 24 \\
1 \cdot 18 \pm 0 \cdot 25\end{array}$ & $\begin{array}{l}148 \pm 18 \\
138 \pm 16 \\
142 \pm 18\end{array}$ \\
\hline $\mathrm{CC} / \mathrm{TT}(n=20)$ & $\begin{array}{l}\text { SFA } \\
\text { CHO } \\
\text { Mediterranean }\end{array}$ & $\begin{array}{l}4.43 \pm 0.61 \\
3.76 \pm 0.64 \\
3.93 \pm 0.73\end{array}$ & $\begin{array}{l}2.75 \pm 0.71 \\
2 \cdot 22 \pm 0.65 \\
2.31 \pm 0.69\end{array}$ & $\begin{array}{l}75 \pm 14 \\
65 \pm 15 \\
67 \pm 17\end{array}$ & $\begin{array}{l}0.69 \pm 0.24 \\
0.73 \pm 0.21 \\
0.74 \pm 0.28\end{array}$ & $\begin{array}{l}1 \cdot 30 \pm 0 \cdot 30 \\
1 \cdot 19 \pm 0 \cdot 25 \\
1 \cdot 26 \pm 0 \cdot 30\end{array}$ & $\begin{array}{l}153 \pm 13 \\
164 \pm 13 \\
149 \pm 16\end{array}$ \\
\hline$P$-value ${ }^{*}$ & $\begin{array}{l}\text { Genotype } \\
\text { Diet } \\
\text { Interaction }\end{array}$ & $\begin{array}{l}0.129 \\
0.000 \\
0.260\end{array}$ & $\begin{array}{l}0.216 \\
0.000 \\
0.136\end{array}$ & $\begin{array}{l}0.454 \\
0.000 \\
0.238\end{array}$ & $\begin{array}{l}0.740 \\
0.268 \\
0.977\end{array}$ & $\begin{array}{l}0.445 \\
0.000 \\
0.344\end{array}$ & $\begin{array}{l}0.203 \\
0.000 \\
0.621\end{array}$ \\
\hline
\end{tabular}

${ }^{*} P$ values calculated by ANOVA.

Apo, apolipoprotein.

investigated as regards HL. Previous studies in rats have shown that HL activity is inhibited by diets rich in saturated fats (Summerfield et al. 1984).

Our study clearly shows that gender interacts with genotype and diet to determine dietary modifications in insulin resistance. Likewise, in the present study, while the female carriers of the $\mathrm{T}$ allele displayed a tendency towards lower insulin resistance following the three dietary periods, no significant differences were observed when compared with the females homozygous for the $\mathrm{C}$ allele. The lack of effect of the $\mathrm{T}$ allele on insulin sensitivity in women is similar to the phenomenon observed in plasma HDL-C levels in response to changes in diet (Gomez et al. 2004). The association of the $-514 \mathrm{C} / \mathrm{T}$ polymorphism with HDL-C levels in a specific gender may be due to differences in exogenous administration or endogenous levels of sex hormones, which may differentially modulate lipoprotein metabolism between males and females. Moreover, because HL activity is regulated by sex-steroid hormones and because HL activity is higher in men than in women, divergent findings could be caused by gender difference, as we observed in our study. The gender difference in HL activity has led some to hypothesize that HL activity is a major determinant of the more atherogenic lipoprotein profile in men compared with women.

Insulin has been assumed to upregulate the activity of HL via insulin-responsive elements in the HL promoter. This has been proposed to explain the associations between hyperinsulinemia and high HL activity (Jansen et al. 1997, Romano et al. 1997). Jansen et al. (1997) observed a positive correlation between plasma levels of insulin and HL activity in non-carriers of the $-514 \mathrm{~T}$ allele, whereas no such relation was noted in carriers of the mutation. The same effect was recorded by Pihlajamaki et al. (2000) who observed an association between insulin resistance and the $-250 \mathrm{G} / \mathrm{A}$ polymorphism in the HL promoter region. Therefore, variants in
HL promoter activity may abolish the ability of insulin to stimulate HL activity. However, whether the promoter polymorphisms of the HL gene could regulate other actions of insulin is not known. Theoretically, changes in serum FFA levels could regulate the expression of peroxisome proliferator-activator receptors and, therefore, insulin sensitivity. Alternatively, the effect of HL on insulin sensitivity could be partly mediated via changes in the amount or distribution of body lipid storage. A third possibility is that changes in HL activity primarily alter serum lipids and secondarily lead to changes in intramyocellular lipid storage; therefore, the HL promoter variant could affect insulin sensitivity in skeletal muscle. Finally, HL may have other currently unknown functions that could affect the ability of insulin to stimulate glucose uptake. In addition, it is noteworthy that the -514 site is at the center of a $\mathrm{CAC}^{*} \mathrm{GGG}$ sequence, almost analogous to the CACGTG motif characteristic of an E-box onto which the upstream stimulatory factors (USF) $1 / 2$ can bind. The latter are transcription factors involved in the regulation of glucose and lipid metabolism in the liver. For instance, USFs are part of the insulin responsive complexes that interact with the fatty acid synthase gene (Wang \& Sul 1997). It is tempting to speculate that the $-514 \mathrm{C} / \mathrm{T}$ substitution would disrupt the E-box analogous sequence and impair the stimulatory regulation exerted by insulin. Interestingly, it has recently been reported that USF proteins can bind to the -514 region, and that the affinity is reduced fourfold by the $-514 \mathrm{C} / \mathrm{T}$ substitution (Botma et al. 2001).

In summary, after ingestion of a saturated fatenriched diet, male carriers of the $-514 \mathrm{~T}$ allele in the promoter region of the HL gene show decreased insulin sensitivity which improves on consuming a carbohydrate-rich diet and a Mediterranean diet. Our results suggest that male carriers of the $-514 \mathrm{~T}$ allele are at greater risk of developing the insulin resistance 

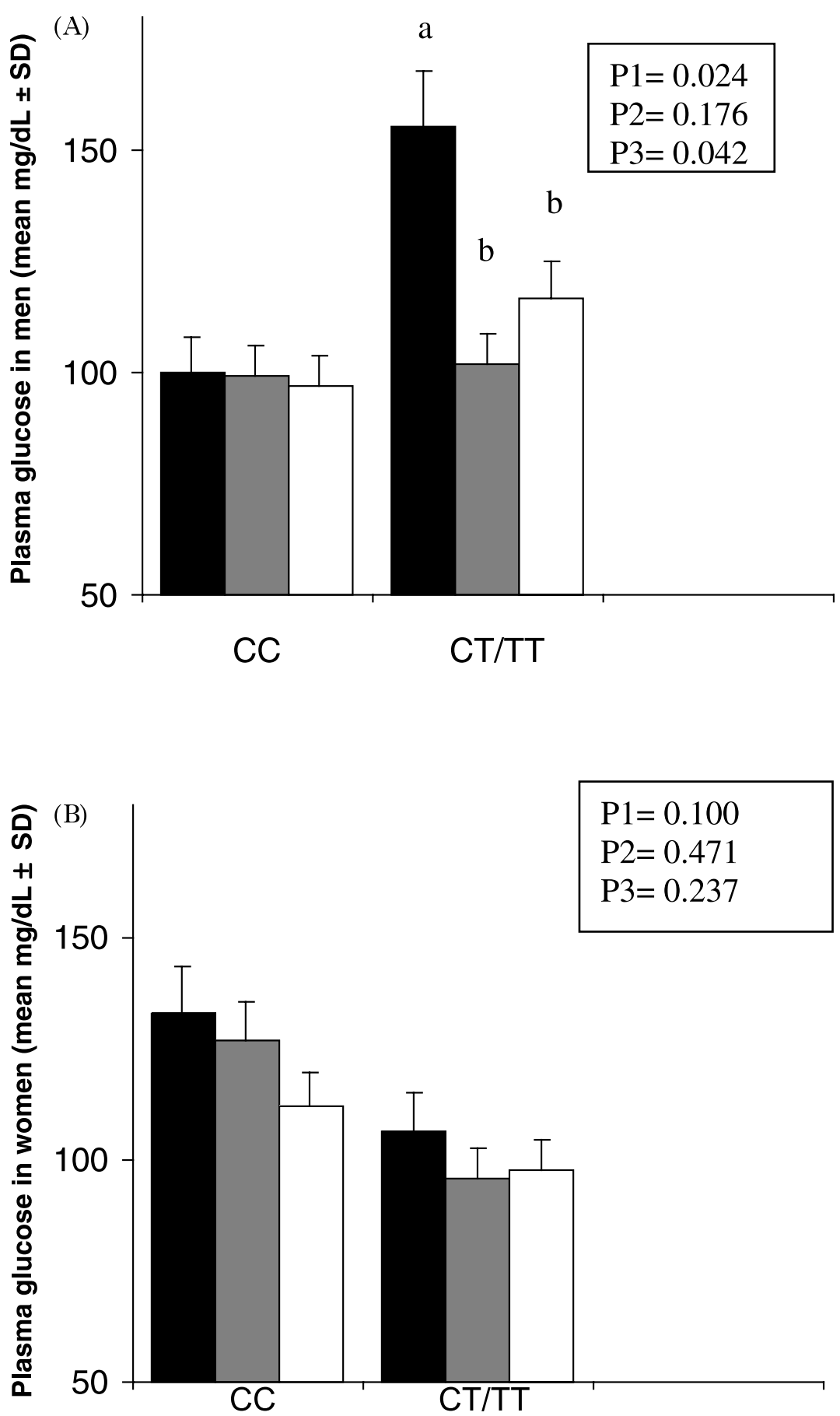

Figure 1 Steady state plasma glucose concentrations in relation to the $-514 \mathrm{C} / \mathrm{T} \mathrm{HL}$ promoter polymorphism after different diets in (A) men and (B) women. The saturated fat enriched diet (SFA) is represented by solid bars; the low-fat, high-carbohydrate diet ( $\mathrm{CHO}$ diet) is represented by shaded bars and the monounsaturated fat-enriched Mediterranean diet is represented by open bars. Multivariate ANOVA for repeated measures are shown: P1, diet effect; P2, genotype effect; P3, genotype by diet interaction. Bars with different letters are significantly different $(P<0.05)$. 
syndrome and type 2 diabetes mellitus when they ingest a diet rich in saturated fat. Detection of this group of subjects may be one way to inhibit the development of type 2 diabetes.

\section{Acknowledgements}

This work was supported by research grants from the CICYT (SAF96/0060, OLI 96/2146 to F P-J, SAF 01/2466-C05 04 to F P-J, SAF 01/03666 to J L-M), the Spanish Ministry of Health (FIS, 98/1531, 01/0449 to J L-M, FIS 99/0949 to F P-J), Fundación Cultural 'Hospital Reina Sofia-Cajasur' (P G), Consejería de Salud, Servicio Andaluz de Salud (PAI 97/58, 98/126, 99/116, 00/212 and 01/243 to J L-M, PAI 97/57, 98/132, 99/165, 00/39 to F P-J, and PAI 01/239 to F F-J), Diputación Provincial de Córdoba (to G M) and Patrimonio Comunal Olivarero (to F P-J). The authors declare that there is no conflict of interest that would prejudice the impartiality of this scientific work.

\section{References}

Allain CG, Poon LS, Chang CSG, Richmond W \& Fu PC 1974 Enzymatic determination of total serum cholesterol. Clinical Chemistry 20 470-475.

Almind K, Bjorbaek C, Vestergaard H, Hansen T, Echwald SM \& Pedersen O 1993 Amino acid polymorphisms of insulin receptor substrate-1 in non-insulin-dependent diabetes mellitus. Lancet 342 828-832.

Association of Official Analytical Chemists. Official Methods of Analysis, 15th edn (modified). Arlington: Association of Official Analytical Chemists, 1990.

Bjontorp P 1994 Fatty acids, hyperinsulinemia, and insulin resistance: which comes first? Current Opinion in Lipidology $\mathbf{5}$ $166-174$.

Bjorbaek C, Echwald SM, Hubricht P, Vestergaard H, Hansen T, Zierath J \& Pedersen O 1994 Genetic variants in promoters and coding region of the muscle glycogen synthase and the insulin-responsive GLUT-4 genes in NIDDM. Diabetes $\mathbf{4 3}$ 976-983.

Botma GJ, Verhoeven AJ \& Jansen H 2001 Hepatic lipase promoter activity is reduced by the $\mathrm{C}-480 \mathrm{~T}$ and G-216A substitutions present in the common LIPC gene variant, and is increased by upstream stimulatory factor. Atherosclerosis 154 625-632.

Bucolo G \& David H 1973 Quantitative determination of serum triglycerides by use of enzymes. Clinical Chemistry 19 476-482.

Friedewald WT, Levy RI \& Fredrickson DS 1972 Estimation of the concentration of low density lipoprotein cholesterol in plasma without the use of preparative ultracentrifuge. Clinical Chemistry 18 499-502.

Fuentes F, López-Miranda J, Sánchez E, Sánchez F, Paez J, Paz-Rojas E, Marín C, Gómez P, Jiménez-Pereperez J, Ordovas JM \& Pérez-Jiménez F 2001 Mediterranean and low-fat diets improve endothelial function in hypercholesterolemic men. Annals of Internal Medicine 134 1115-1119.

Gómez P, López-Miranda JL, Marín C, Bellido C, Moreno JA, Moreno R, Pérez-Martínez P \& Pérez-Jiménez F 2004 Influence of the $-514 \mathrm{C} / \mathrm{T}$ polymorphism in the promoter of the hepatic lipase gene on postprandial lipoprotein metabolism. Atherosclerosis $17473-79$
Guerra R, Wang J, Grundy SM \& Cohen JC 1997 A hepatic lipase (LIPC) allele associated with high plasma concentrations of high density lipoprotein cholesterol. PNAS 94 4532-4537.

Harano Y, Ohgaku S, Hidaka H, Haneda K, Kikkawa R, Shigeta Y \& Abe H 1977 Glucose, insulin and somatostatin infusion for the determination of insulin sensitivity. Fournal of Clinical Endocrinology and Metabolism 45 1124-1127.

Human Nutrition Information Service Department of Agriculture 1987 Composition of foods. Agriculture Handbook no. 8. Washington DC: US Government Printing Office.

Jansen H, Verhoeven A, Weeks L, Kastelein JJ, Halley DJ, van den Ouweland A, Jukema JW, Seidell JC \& Birkenhager JC 1997 Common C-to-T substitution at position -480 of the hepatic lipase promoter associated with lowered lipase activity in coronary artery disease patients. Arteriosclerosis, Thrombosis and Vascular Biology $172837-2842$.

Kusari J, Verma US \& Buse JB 1991 Analysis of the gene sequences of the insulin receptor and the insulin-sensitive glucose transporter (GLUT-4) in patients with common type non-insulin-dependent diabetes mellitus. Fournal of Clinical Investigation 88 1323-1330.

Laws A, Jeppesen JL, Maheux PC, Schaal P, Chen YD \& Reaven GM 1994 Resistance to insulin-stimulated glucose uptake and dyslipidemia in Asian Indians. Arteriosclerosis, Thrombosis and Vascular Biology 14 917-922.

Mayer-Davis EJ, Monaco JH, Hoen HM, Carmichael S, Vitolins MZ, Rewers MJ, Haffner SM, Ayad MF, Bergman RN \& Karter AJ 1997 Dietary fat and insulin sensitivity in a triethnic population: the role of obesity. The Insulin Resistance Atherosclerosis Study (IRAS). American Fournal of Clinical Nutrition 67 79-87.

Moller DE, Bjorback C \& Vidal-Puig A 1996 Candidate genes for insulin resistance. Diabetes Care 19 396-400.

National Cholesterol Education Program. Second report of the expert panel on detection, evaluation, and treatment of high blood cholesterol in adults (Adult Treatment Panel II). Circulation 199489 1329-1745.

Pérez-Jiménez F, López-Miranda J, Pinillos MD, Gómez P, Paz-Rojas E, Montilla P, Marín C, Velasco MJ, Blanco-Molina A, Jiménez Pereperez JA \& Ordovas JM. 2001 A Mediterranean diet and a high-carbohydrate diet improve glucose metabolism in healthy young persons. Diabetología 44 2038-2043.

Pérez-Martínez P, Gómez P, Paz E, Marín C, Gavilan Moral E, López-Miranda J, Ordovas JM, Fernandez de la Puebla RA \& Pérez-Jiménez F 2001 Interaction between smoking and the SstI polymorphism of the apo C-III gene determines plasma lipid response to diet. Nutrition Metabolism and Cardiovascular Diseases 11 237-243.

Pihlajamaki J, Karjalainen L, Karhapaa P, Vauhkonen I, Taskinen MR, Deeb SS \& Laakso M 2000 G-250A substitution in promoter of hepatic lipase gene is associated with dyslipidemia and insulin resistance in healthy control subjects and in members of families with familial combined hyperlipidemia. Arteriosclerosis, Thrombosis and Vascular Biology 20 1789-1795.

Purnell JQ \& Brunzell JD 1997 The central role of dietary fat, non carbohydrate in the insulin resistance syndrome. Current Opinion in Lipidology 817-822.

Reynet C \& Kahn CR 1993 Rad: a member of the Ras family overexpressed in muscle of type II diabetic humans. Science $\mathbf{2 6 2}$ 1441-1444.

Romano G, Patti L, Innelli F, Di Marino L, Annuzzi G, Iavicoli M, Coronel GA, Riccardi G \& Rivellese AA 1997 Insulin and sulfonylurea therapy in NIDDM patients: are the effects on lipoprotein metabolism different even with similar blood glucose control? Diabetes 46 1601-1606.

Ruiz-Gutierrez V, Prada JL \& Pérez-Jiménez F 1993 Determination of fatty acids and triacylglycerol composition of human very low density lipoproteins. Fournal of Chromatography 662 $117-134$. 
Shimizu S, Inoue K, Tani Y \& Yamada H 1979 Enzymatic microdetermination of serum free fatty acids. Analytical Biochemistry 98 341-345.

Steiner G 1991 Altering triglyceride concentrations changes insulin-glucose relationships in hypertriglyceridemic patients. Diabetes Care 14 1077-1081.

Storlien LH, Pan DA, Kriketos AD \& Baun LA 1993 High fat diet induces fat resistance. Lessons and implications from animal studies. Annals of the New York Academy of Sciences 683 82-90.

Summerfield JA, Applebaum-Bowden D \& Hazzard WR 1984 Effects of diet and age on lipoprotein lipase and hepatic triglyceride lipase activities in the rat. Proceedings of the Society for Experimental Biology and Medicine 175 158-163.

Walston J, Silver K, Bogardus C, Knowler WC, Celi FS, Austin S, Manning B, Strosberg AD, Stern MP, Raben N et al. 1995 Time of onset of non-insulin dependent diabetes mellitus and genetic variation in the $\beta 3$-adrenergic-receptor gene. New England Fournal of Medicine 333 343-347.
Wang D \& Sul HS 1997 Upstream stimulatory factor binding to the E-box at -65 is required for insulin regulation of the fatty acid synthase promoter. Fournal of Biological Chemistry 272 26367-26374.

Warnick GR, Benderson J \& Alberts JJ 1982 Dextran sulfate-Mg+ precipitation procedure for quantitation of high density lipoprotein cholesterol. Clinical Chemistry 28 1379-1388.

Zambon A, Deeb SS, Hokanson JE, Brown BG \& Brunzell JD 1998 Common variants in the promoter of the hepatic lipase gene are associated with lower levels of hepatic lipase activity, buoyant LDL, and higher $\mathrm{HDL}_{2}$ cholesterol. Arteriosclerosis, Thrombosis and Vascular Biology 18 1723-1729.

Received 8 October 2004

Accepted 21 December 2004 